\title{
Meningite Bacteriana Aguda como Doença Ocupacional
}

\author{
Acute Bacterial Meningitis as an Occupational Disease
}

\author{
Diana SEIXAS ${ }^{1}$, Ana LEBRE${ }^{1}$, Pedro CRESPO ${ }^{1}$, Eugénia FERREIRA ${ }^{1}$, José Eduardo SERRA ${ }^{1}$, José Gabriel SARAIVA \\ DA CUNHA ${ }^{1}$ \\ Acta Med Port 2014 Jul-Aug;27(4):519-521
}

\section{RESUMO}

Streptococcus suis é um agente zoonótico com distribuição mundial, atualmente responsável por mais de 700 casos reportados em humanos. Atinge quase em exclusivo indivíduos do sexo masculino com exposição a suínos ou à sua carne, classificando-se neste contexto como uma doença ocupacional. Os autores apresentam um caso de meningite bacteriana aguda por este agente infeccioso, num homem de 44 anos com antecedentes de etilismo crónico cuja atividade profissional consistia em assar leitões num restaurante. A análise microbiológica do sangue e do LCR revelou S. suis, agente etiológico desta infecção. Foi tratado empiricamente com ceftriaxona, completando 14 dias de antibioterapia com resolução total do quadro. Reveem-se os casos previamente descritos em Portugal. Em todos foi possível identificar exposição a carne de porco crua. Alerta-se para a importância deste agente infeccioso em Portugal, onde possivelmente se encontrará sub-diagnosticado.

Palavras-chave: Doenças Ocupacionais; Exposição Ocupacional; Meningite Bacteriana; Infecções Estreptocócicas; Streptococcus suis; Portugal.

\section{ABSTRACT}

Streptococcus suis is a zoonotic pathogen with worldwide distribution, responsible for more than 700 human cases globally reported. This infection affects mostly men, exposed to pig or pork, which leads to its usual classification as an occupational disease. We report a case of acute bacterial meningitis in a 44 years old male. According to his past medical history, the patient had alcohol consumption and worked in a restaurant as a piglet griller. Microbiological examination of blood and CSF revealed S. suis. After 14 days of ceftriaxone the patient fully recovered. The authors review the clinical reports previously described in Portugal. In all of them was possible to identify risk exposition to pork. We alert to this microorganism's importance in Portugal where it is probably underdiagnosed.

Keywords: Occupational Diseases; Occupational Exposure; Meningitis, Bacterial; Streptococcal Infections; Streptococcus suis; Portugal.

\section{INTRODUÇÂO}

Streptococcus suis é um microrganismo com distribuição mundial, tendo sido pela primeira vez isolado em $1954 .^{1}$ O primeiro caso de infecção reconhecida em humanos foi documentado 14 anos mais tarde na Dinamarca. ${ }^{2}$ Os suínos são o seu principal reservatório, a partir dos quais a infecção é transmitida aos humanos. Nas séries descritas há ausência quase absoluta de crianças, sendo a população afectada maioritariamente masculina, com idade média relativamente alta (47-55 anos), ${ }^{3}$ características que conduziram à sua classificação como doença ocupacional. Efetivamente, indivíduos cuja atividade implique contacto com estes animais ou a manipulação da sua carne têm risco acrescido de adoecer face à população em geral. ${ }^{4}$

$\mathrm{Na}$ última década os relatos de infecção causada por S. suis têm vindo a aumentar, devido à ocorrência de surtos epidémicos no Sudeste Asiático, onde a densidade de suínos é elevada, ${ }^{5,6}$ pelo que é também classificada como zoonose emergente. ${ }^{7}$

Além de descreverem o presente caso clínico, os autores revêm também os relatos de doença por $S$. suis publicados em Portugal: epidemiologia inerente, apresentação e evolução, alertando para um agente cuja prevalência não deve ser menosprezada.

\section{CASO CLÍNICO}

Um homem de 44 anos foi admitido no Serviço de Urgência a 18 de Abril de 2011, com um quadro de mialgias, vómitos e letargia com 48 horas de evolução. Como antecedentes pessoais apresentava etilismo, com consumo diário regular de $30 \mathrm{~g}$ de álcool. Sem outros dados epidemiológicos relevantes, exceptuando trabalhar na cozinha de um restaurante na região de Coimbra, assando leitões.

Ao exame objectivo apresentava-se obnubilado, febril (temperatura auricular $38,4^{\circ} \mathrm{C}$ ), hemodinamicamente estável (TA 130/70 mmHg, FC 78 bpm), sem alterações auscultatórias ou cutâneas. No exame neurológico manifestava rigidez da nuca e presença dos sinais de Kernig e Brudzinsky. Os parâmetros analíticos indiciavam alterações inflamatórias, com PCR $8,4 \mathrm{mg} / \mathrm{dL}$, CK $858 \mathrm{U} / \mathrm{L}$, leucocitose $17,3 \times 10^{\%} / \mathrm{L}$ (neutrofilia de 92,1\%). Radiologicamente não se identificou atingimento pulmonar ou alterações na TC-CE. Foi realizada punção lombar, com saída de líquor turvo, cujo estudo citoquímico evidenciou hiperproteinorráquia (611 mg/dL), hipoglicorráquia (<1 mg/dL) e citologia com 
aumento da contagem dos leucócitos $\left(1600 / \mathrm{mm}^{3}\right)$. Apesar da coloração de Gram evidenciar abundância de diplococos Gram positivo, a pesquisa de antigénios solúveis de S. pneumoniae foi negativa. Diagnosticada uma meningite bacteriana aguda, foi iniciado o tratamento empírico com ceftriaxona na dose de $4 \mathrm{~g} /$ dia e o doente foi internado no Serviço de Doenças Infecciosas.

Posteriormente foram disponibilizados os resultados dos exames microbiológicos, confirmando-se a presença de $S$. suis no sangue e LCR. Cumpriu 14 dias de antibioterapia, com boa evolução clínica e normalização dos parâmetros analíticos. Recebeu alta totalmente assintomático, tendo sido orientado para o seu médico assistente.

\section{DISCUSSÃO}

S. suis é um coco Gram positivo, anaeróbio facultativo. É comensal nas vias aéreas superiores, aparelho reprodutivo e digestivo dos suínos afectados, que constituem o seu principal reservatório. ${ }^{4,8}$ Estes podem ser portadores assintomáticos ou adoecerem, transmitindo a infecção entre si, por via vertical ou horizontal, e podendo infectar os humanos. ${ }^{3,7}$ Nestes a transmissão ocorre pela entrada direta de $S$. suis na corrente sanguínea, através de soluções de continuidade cutâneas ou por via oral. ${ }^{8}$

Não existe evidência de transmissão inter-humana, discutindo-se se o aumento dos casos registado se deve à dispersão de clones com capacidade infectante aumentada ou se é atribuível a maior acuidade diagnóstica atual. ${ }^{9,10}$

Manifesta-se, geralmente, sob a forma de meningite bacteriana aguda (MBA), podendo também ocorrer como sépsis/choque séptico, endocardite, artrite, pneumonia, endoftalmite ou espondilodiscite. ${ }^{11}$ Nos surtos epidémicos ocorridos na China o choque séptico, com características idênticas à síndroma do choque tóxico, foi a apresentação mais frequente, com um curso fulminante, na grande maioria dos casos. ${ }^{3,6,7}$

S. suis é, habitualmente, sensível aos $\beta$-lactâmicos, pelo que o tratamento com penicilina, ampicilina ou ceftria- xona é correto. ${ }^{2}$

Tal como sucede na meningite pneumocócica, é fundamental a instituição precoce da terapêutica, em dosagem e duração sobreponíveis aos utilizados naquela doença. ${ }^{4}$ Ainda que controverso,,$^{12}$ o uso de dexametasona, equaciona-se na tentativa de debelar a hipoacusia neurossensorial, sequela desta meningite em mais de $50 \%$ dos casos. ${ }^{3}$

O presente caso clínico é o quinto relato de $S$. suis em Portugal ${ }^{13-15}$ (Tabela 1). Coincidiu tratarem-se de indivíduos do sexo masculino, com uma mediana de idades de 35 $( \pm 9)$ anos, significativamente inferior à média registada na literatura mundial. Foi identificada exposição de risco comum (carne de porco crua), tendo sido a MBA a apresentação clínica transversal, de encontro à prevalência descrita. Foram tratados com sucesso com penicilina ou ceftriaxona, registando-se hipoacusia sequelar em apenas um dos casos revistos.

A exploração suína, em condições precárias com ventilação inadequada, parece potenciar a transmissão de $S$. suis. A prevenção passa pela melhoria da higiene dessas infraestruturas: ${ }^{7}$ S. suis resiste horas a semanas nas carcaças e fezes dos animais com temperatura e humidade adequadas, mas é facilmente eliminado com lixívia a $5 \%$ numa diluição de 1:799.,37 Com maior valor em contexto epidémico está também disponível uma vacina inativada, resultante de estirpes virulentas isoladas em animais doentes. ${ }^{7}$

Relativamente aos humanos, a chave da prevenção reside, sobretudo, no cuidado exigido no contacto com suínos e a sua carne. A educação dos grupos de maior risco é essencial, fomentando a utilização de luvas e máscaras e a cuidada manipulação da carne de porco, evitando cortes e abrasões. Esta deve ser confecionada até ao desaparecimento do tom rosáceo e evitada a contaminação cruzada entre a carne cozinhada e a crua, pelo contacto entre si ou entre os utensílios utilizados. Finalmente, é indispensável a higienização posterior das mãos em qualquer uma das situações previamente descritas. ${ }^{7}$

Tabela 1 - Caracterização sumária dos casos de meningite bacteriana aguda por S. suis, reportados na literatura em Portugal

\begin{tabular}{|c|c|c|c|c|c|c|c|c|}
\hline Caso & $\begin{array}{l}\text { Idade/ } \\
\text { Sexo }\end{array}$ & Ant & Profissão & $\begin{array}{l}\text { Duração dos } \\
\text { sintomas até ao } \\
\text { diagnóstico }\end{array}$ & $\begin{array}{c}\text { Forma de } \\
\text { apresentação }\end{array}$ & Tratamento & Evolução & Referência \\
\hline 1 & $30 / \hbar$ & ? & Talhante & 3 dias & MBA & Penicilina G & Favorável & $\begin{array}{c}\text { Alves } \\
\text { Pereira }^{13}\end{array}$ \\
\hline 2 & $26 /$ ठิ & $?$ & Talhante & 2 dias & MBA & Penicilina G & $\begin{array}{l}\text { Hipoacusia } \\
\text { bilateral } \\
\text { sequelar }\end{array}$ & $\begin{array}{c}\text { Alves } \\
\text { Pereira }^{13}\end{array}$ \\
\hline 3 & $46 / \sigma^{\lambda}$ & Saudável & Talhante & 2 dias & MBA & Ceftriaxona & Favorável & Pinto IV ${ }^{14}$ \\
\hline 4 & $32 / \pi$ & Saudável & $\begin{array}{c}\text { Participação } \\
\text { em matança } \\
\text { do porco } \\
\text { tradicional }\end{array}$ & 4 dias & MBA & $\begin{array}{l}\text { Ceftriaxona/ } \\
\text { Penicilina }\end{array}$ & Favorável & Taipa $\mathrm{R}^{15}$ \\
\hline 5 & $44 / \pi$ & Etilismo & $\begin{array}{l}\text { Assador de } \\
\text { leitões }\end{array}$ & 2 dias & MBA & Ceftriaxona & Favorável & $\begin{array}{l}\text { Presente } \\
\text { caso }\end{array}$ \\
\hline
\end{tabular}




\section{CONCLUSÃO}

Os viajantes formam um grupo particular pela tentação de experimentarem iguarias da área para onde se deslocam, e que podem envolver alimentos mal cozinhados. ${ }^{8}$ Este comportamento, considerado de risco, deverá ser abordado na Consulta do Viajante.

Além de promover a educação dos indivíduos ligados à indústria suína e ao manuseio desta carne, a ocorrência destes casos em Portugal deverá, também, sensibilizar os clínicos para o diagnóstico e despertar a atenção dos microbiologistas, já que alguns autores advogam que este microrganismo é muitas vezes erroneamente classificado como Streptococcus spp ou S. viridans, entre outros. ${ }^{3}$

\section{REFERÊNCIAS}

1. Field HI, Buntain D, Done JT. Studies on pig mortality. I. Streptococcal meningitis and arthritis. Vet Rec. 1954;66:453-5.

2. Perch B, Kristjansen P, Skadhange K. Group R streptococci pathogenic for man. Two cases of meningitis and one fatal case of sepsis. Acta Path Microbiol Scand. 1968;74:69-76.

3. Wertheim HF, Nghia HD, Taylor W, Schultsz C. Streptococcus suis: an emerging human pathogen. Clin Infect Dis. 2009;48:617-25.

4. Zalas-Wiecek P, Michalska A, Grabczewska E, Olczak A, Pawlowska M, Gospodarek E. Human meningitis caused by Streptococcus suis. J Med Microbiol. 2013;62:483-5.

5. Choi SM, Cho BH, Choi KH, Nam TS, Kim JT, Park MS, et al. Meningitis caused by Streptococcus suis: case report and review of the literature. J Clin Neurol. 2012;8:79-82.

6. Yu H, Jing $\mathrm{H}$, Chen $\mathrm{Z}$, Zheng $\mathrm{H}$, Zhu X, Wang $\mathrm{H}$, et al. Human streptococcus suis outbreak, Sichuan, China. Emerg Infect Dis. 2006;12:91420.

7. Lun ZR, Wang QP, Chen XG, Li AX, Zhu XQ. Streptococcus suis: an emerging zoonotic pathogen. Lancet Infect Dis. 2007;7:201-9.

8. Arends JP, Hartwig N, Magriet R, Zanen HC. Carrier rate of Streptococcus suis capsular type 2 un palatine tonsils of slaughtered pigs. J Clin
Por último insistimos na necessidade transversal da realização de uma história clínica detalhada: atentar na epidemiologia persiste como uma ferramenta privilegiada para abranger hipóteses diagnósticas e equacionar agentes etiológicos diversos.

\section{CONFLITOS DE INTERESSE}

Não existem, por parte dos Autores, conflitos de interesse a declarar.

\section{FONTES DE FINANCIAMENTO}

Não existem, por parte dos Autores, fontes de financiamento a declarar.

Microbiol. 1984;20:945-7.

9. Gottshalk M, Xu J, Segura M. Streptococcus suis: a new emerging or an old neglected zoonotic pathogen? Future Microbiol. 2010;5:371-91.

10. Fittipaldi N, Segura M, Grenier D, Gottschalk M. Virulence factors involved in the pathogenesis of the infection caused by the swine pathogen and zoonotic agent Streptococcus suis. Future Microbiol. 2012;7:259-79.

11. Staats JJ, Feder I, Okwumabua O, Chengappa MM. Streptococcus suis past and present. Vet Res Commun. 1997;21:381-407.

12. Heyderman RS, British Infection Society. Early management of suspected bacterial meningitis and meningococcal septicaemia in immunocompetent adults-second edition. J Infect. 2005;50:373-4.

13. Alves Pereira A, Lecour H, Sarmento A, Candeias J, Costa A, Pereira C Meningitis caused by Streptococcus suis type II. Arq Med. 1989;3:135-6.

14. Pinto IV, Caixinha JP, Castro V, Marques A, Fonseca A, Vera J. Infecção por Streptococcus suis: uma causa rara de meningite no homem. Rev Port Doenc Infec. 2005;2:34-5.

15. Taipa R, Lopes V, Magalhães M. Streptococcus suis meningitis: first case report from Portugal. J Infect. 2008;56:482-3. 


\section{Meningite Bacteriana Aguda como Doença Ocupacional \\ Acta Med Port 2014:27:519-521}

Publicado pela Acta Médica Portuguesa, a Revista Científica da Ordem dos Médicos

Av. Almirante Gago Coutinho, 151

1749-084 Lisboa, Portugal.

Tel: +351218428215

E-mail: submissao@actamedicaportuguesa.com

www.actamedicaportuguesa.com

ISSN:0870-399X | e-ISSN: 1646-0758

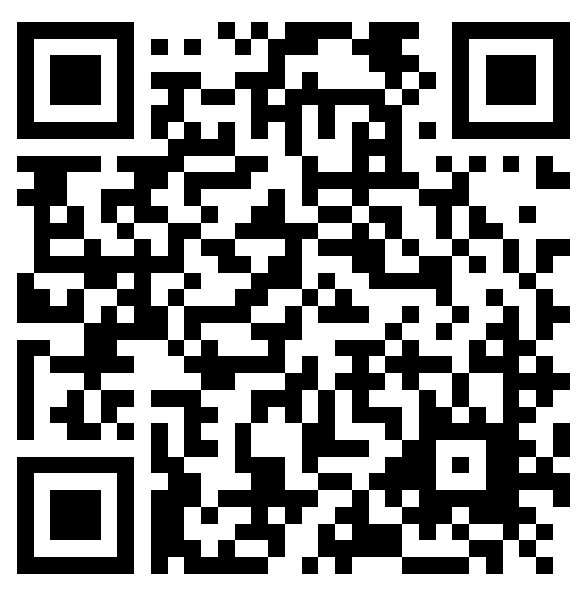

